\title{
Mucinous Adenocarcinoma in Body Fluid Cytology.
}

\author{
Rajat Kumar $^{1 *}$, M. Rana ${ }^{1}$, Prashant ${ }^{2}$ \\ 'Dept of Pathology, Central Hospital, Singrauli. INDIA \\ ${ }^{2}$ Dept of Medicine, Central Hospital, Singrauli. INDIA
}

\section{Dear Sir,}

Body fluid Cytology can show lot of things if we pay attention right from collection till finalizing the results. Here we would like to present a case of 70 yrs. old lady who present with recurrent ascites with mild hepatitis. Fever, fatigue \& decreased appetite also seen. USG shows Mild to moderate ascites with hepatitis. Liver enzymes are mild elevated. Haemoglobin is on lower side (11gm\%), urine and stool examination were unremarkable. Liver scan shows mild hepatitis. Viral Hepatitis markers (A, B, C) are negative.

Paracentesis done and about $1500 \mathrm{ml}$ fluid drained under aseptic conditions. We collect fluid in 05 separate bottles having $10 \mathrm{ml}$ fluids in each. $3^{\text {rd }}$ bottle has been centrifuged at 3000RPM for 30 mins and smear prepared and stained with Gimsa, PAP, Rapid H \& E. Examination done under 40X \& 100X magnification. Microscopic Examination shows:

Total Cell Count $=12,00$ cells/cumm, Atypical/Mesothelial cells $=89 \%$, Lymphocytes $=8 \%$, Neutrophils $=03 \%$.

Smear prepared from centrifuged precipitate shows tumor cells in 3D clusters, honeycomb pattern, singles and groups. Individual tumor cells are showing signet ring pattern with tight cohesive clusters. Hyperchromatic pleomorphic cells with 1-2 prominent nucleoli in mucinous granular background. Plenty of reactive mesothelial cells having round nucleus with thin rim of cytoplasm (Lacy skirt pattern), RBC's, Lymphocytes \& Neutrophils noted in background. (Pic.1) (Pic.2)

\section{Diagnosis given as Metastatic Adenocarcinoma probably Mucinous Adenocarcinoma.}

Further Investigation done like CA-125(Ovarian tumor marker), which was very high (465IU/L) and CA19.9(GI tumor marker) was within normal limits.

MRI Pelvis shows Bilateral Ovarian Carcinoma with Omental Deposits and tense ascites. CA-125 and MRI confirm our diagnosis and detect primary tumor is in Ovary.

New onset abdominal ascites can sometimes present a diagnostic challenge. Portal hypertension due to cirrhosis is the most common cause of ascites (1), and would certainly be the most likely etiology of ascites in any patient with a prior history of chronic liver disease. Paracentesis provides both therapeutic and diagnostic benefit, allowing for fluid analysis that may identify its etiology, clarifying the source of pathology as either hepatic, cardiac, infectious or malignant.(2) Ascites of malignant aetiology appears in only $10 \%$ of all ascites cases.(3) Malignant ascites most frequently presents in gynaecological and gastrointestinal carcinomas. A combination of malignant ascites and carcinomatosis of the peritoneum is present in $15-30 \%$ of cases.(4) The presence of malignant cells in washings is also an independent, negative prognostic factor in patients with advanced-stage disease.

According to a study by Zuna et al, the sensitivity of peritoneal cytology was $82.9 \%$ and specificity was $98.1 \%$. (5) \& study by Cheng et al, sensitivity of peritoneal fluid cytology was $94 \%$.

The result of primary cytology of ascitic fluid is an important parameter in the diagnosis, staging, therapeutic approach and disease prognosis. The result of secondary cytology after the treatment is also an important independent prognostic marker which is highly correlated with the optimal effect of surgical treatment, recurrence and overall survival rate.(6)

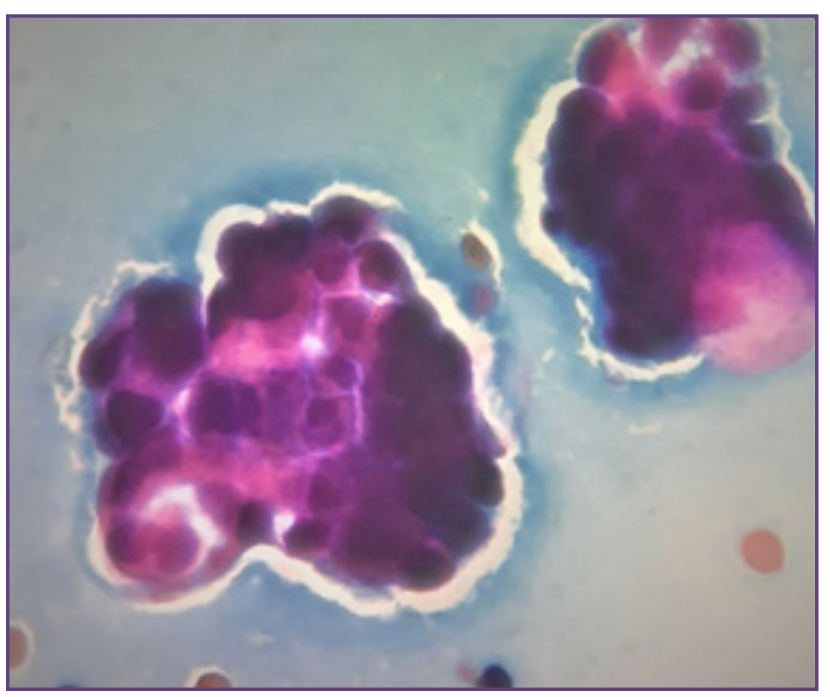

Fig. 1: (PAP 40X) Tumor cells with mucinous background. 


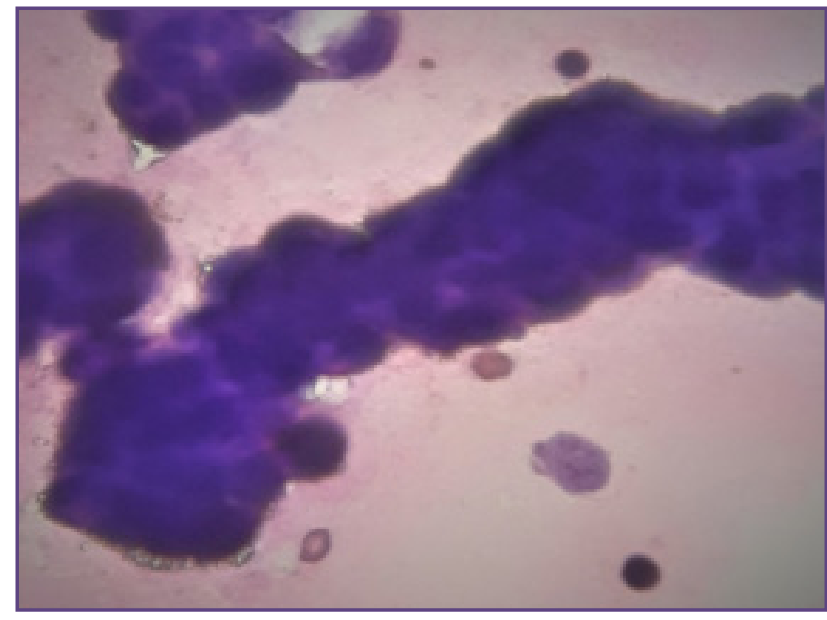

Fig. 2: (Giemsa 40X) Tumor cells in cohesive cluster.

\section{Acknowledgement}

I thankful to Dr. M. Rana (Gynaecologist), Central Hospital, NCL, Singrauli-486889(MP) \& my Lab. Technicians especially M/s. Anjani Upadhya, Central Hospital, Singrauli-486889 for their kind support and help. I also thankful to Dr. Prasant Josh (Medical Consultant), Central Hospital, Singrauli-486889 (MP) for regular follow up of patient.

\section{Source of Funding}

None

\section{Conflicting of Interest}

None

\section{References}

1. Pedersen JS, Bendtsen F, Møller S. Management of cirrhotic ascites. Therapeutic Advances in Chronic Disease 6: 2015:124-137.

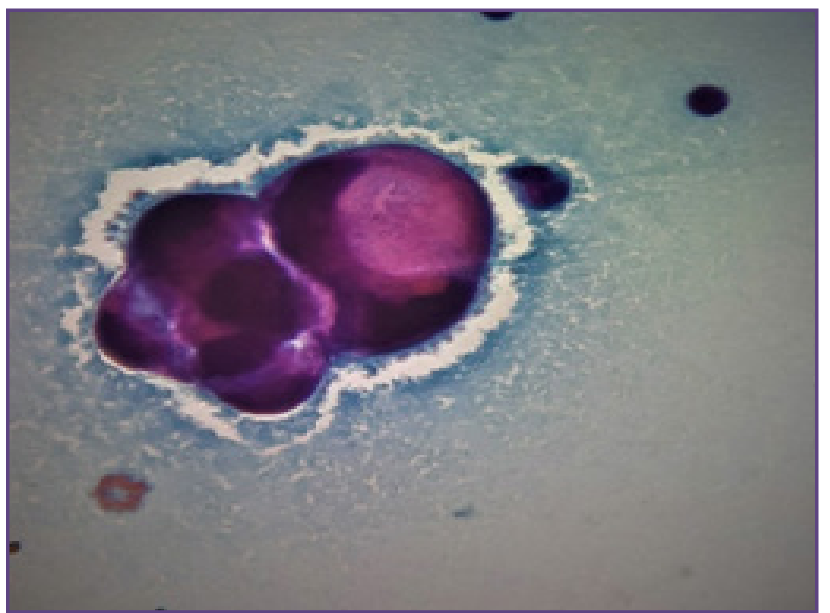

Fig. 3: (PAP 100X) 3D cluster of tumor cells in signet ring cell pattern with mucinous background.

2. Gadani A, Yfantis H, Xie G, Quezada S. A Case of Metastatic Gastric Signet Ring Cell Carcinoma Presenting as Tuberculous Peritonitis in an HIV/HCV Coinfected Patient. Colorec Cancer. 2017:Vol.3 No.2::14.

3. Runyon BA. Care of patients with ascites. N Engl J Med. 1994;330:337-42.

4. Suma L, Thomas J. Malignant ascites: a review of prognostic factors, pathophysiology and therapeutic measures. World J Gastrointest Surg. 2012;4:87-95.

5. Zuna RE, Behrens AJ. Peritoneal washing cytology in gynecologic cancers: long-term follow-up of 355 patients. ActaCytol. 1996;88:980-7.

6. Cheng L, Wolf NG, Rose PG, Rodriguez M, AbdulKarim FW. Peritoneal washing cytology of ovarian tumors of low malignant potential: correlation with surface ovarian involvement and peritoneal implants. Acta Cytol. $1998 ; 42: 1091-4$

*Corresponding author:

Dr. Rajat Kumar, Dy. M.S, Central Hospital, Singrauli-486889 INDIA

Phone: +91 9936905657

Email: rajat.kumar5060@gmail.com.

Financial or other Competing Interests: None.

Date of Submission : 12/01/2020

Date of Acceptance : 01/06/2020

Date of Publication : 29/07/2020 